\title{
Advances in Multiple Sclerosis Research-Series I
}

\author{
Vasso Apostolopoulos $1, * \mathbb{C}$ and John Matsoukas $1,2,3$ \\ 1 Institute for Health and Sport, Victoria University, Melbourne 8001, Australia; imats1953@gmail.com \\ 2 NewDrug, Patras Science Park, 26500 Patras, Greece \\ 3 Department of Physiology and Pharmacology, Cumming School of Medicine, University of Calgary, Calgary, \\ AB T2N 4N1, Canada \\ * Correspondence: vasso.apostolopoulos@vu.edu.au; Tel.: +613-9919-2025
}

Received: 15 October 2020; Accepted: 25 October 2020; Published: 29 October 2020

check for updates

\begin{abstract}
Designing immunotherapeutics, drugs, and anti-inflammatory reagents has been at the forefront of autoimmune research, in particular, multiple sclerosis, for over 20 years. Delivery methods that are used to modulate effective and long-lasting immune responses have been the major focus. This Special Issue, "Advances in Multiple Sclerosis Research-Series I", focused on delivery methods used for immunotherapeutic approaches, drug design, anti-inflammatories, identification of markers, methods for detection and monitoring MS and treatment modalities. The issue gained much attention with 20 publications, and, as a result, we launched Series II with the deadline for submission being 30 April 2021.
\end{abstract}

Keywords: multiple sclerosis; MS; vaccine; immunomodulation; carriers; MS drugs

\section{Multiple Sclerosis}

The World Health Organization estimates that globally, more than 2.5 million people are affected by multiple sclerosis (MS). With the global population growing to an unparalleled height of 7.0 billion in 2011 and recently reaching 7.8 billion (10 October 2020)—it is estimated to reach 8.5 billion by 2030 and 9.7 billion by 2050 - the incidence and onset of MS in young adults is expected to rise exponentially, with an estimate of 2.3 million people living with MS globally. Clinical isolated syndrome is a type of MS which may or may not progress. As such, a person will experience a neurological episode lasting at least $24 \mathrm{~h}$ and resulting in damage to the central nervous system (CNS). There are three main subtypes of MS, (i) relapse/remitting MS (RRMS) accounting for $85 \%$ of MS cases, with 50\% progressing to (ii) secondary progressive MS (SPMS), with (iii) 15\% of those diagnosed at onset of primary progressive MS (PPMS) type. It is possible that RRMS patients can remain in that state for up to 30 years, whilst $8 \%$ develop a more aggressive disease, named highly active RRMS (HARRMS). In rare occasions, up to 5\% are progressive relapsing MS type (PRMS), which is characterized by progressive worsening of the condition from the onset, similar to PPMS.

MS is characterized as a chronic demyelinating disorder of the CNS with inflammatory cells infiltrating around the nerve, leading to demyelination of the myelin sheath and immune attack to myelin basic protein (MBP), proteolipid protein (PLP) and myelin oligodendrocyte glycoprotein (MOG). Inflammatory cells which have been found to be involved in MS include macrophages, T helper type 1 (Th1) cells, Th17 cells, CD8+ T cells and B cells secreting auto-antibodies [1-3]. More recently, it has been shown that tetraspanin-32 is significantly downregulated in Th cells. Tetraspanin-32 controls the development of autoimmune responses, and in EAE models in mice, tetraspanin-32 is significantly expressed at lower levels on activated or encephalitogenic $\mathrm{T}$ cells compared to naïve Th cells. In the study by Basile and Cavalli et al., it was noted that tetraspanin-32 was downregulated in memory $\mathrm{T}$ cells and was further decreased upon ex vivo restimulation (Figure 1) [4]. Likewise, myelin-specific 
memory T cells and peripheral blood mononuclear cells (PBMC) from patients with MS also expressed lower levels of tetraspanin-32 compared to memory $\mathrm{T}$ cells from healthy subjects. In addition, MS patients with early relapses compared to those with a longer, stable disease expressed lower levels of tetraspanin-32 on their PBMC [4]. Hence, tetraspanin-32 is involved in immune responses underlying the pathophysiology of MS, and could be a viable diagnostic marker or therapeutic target against MS.

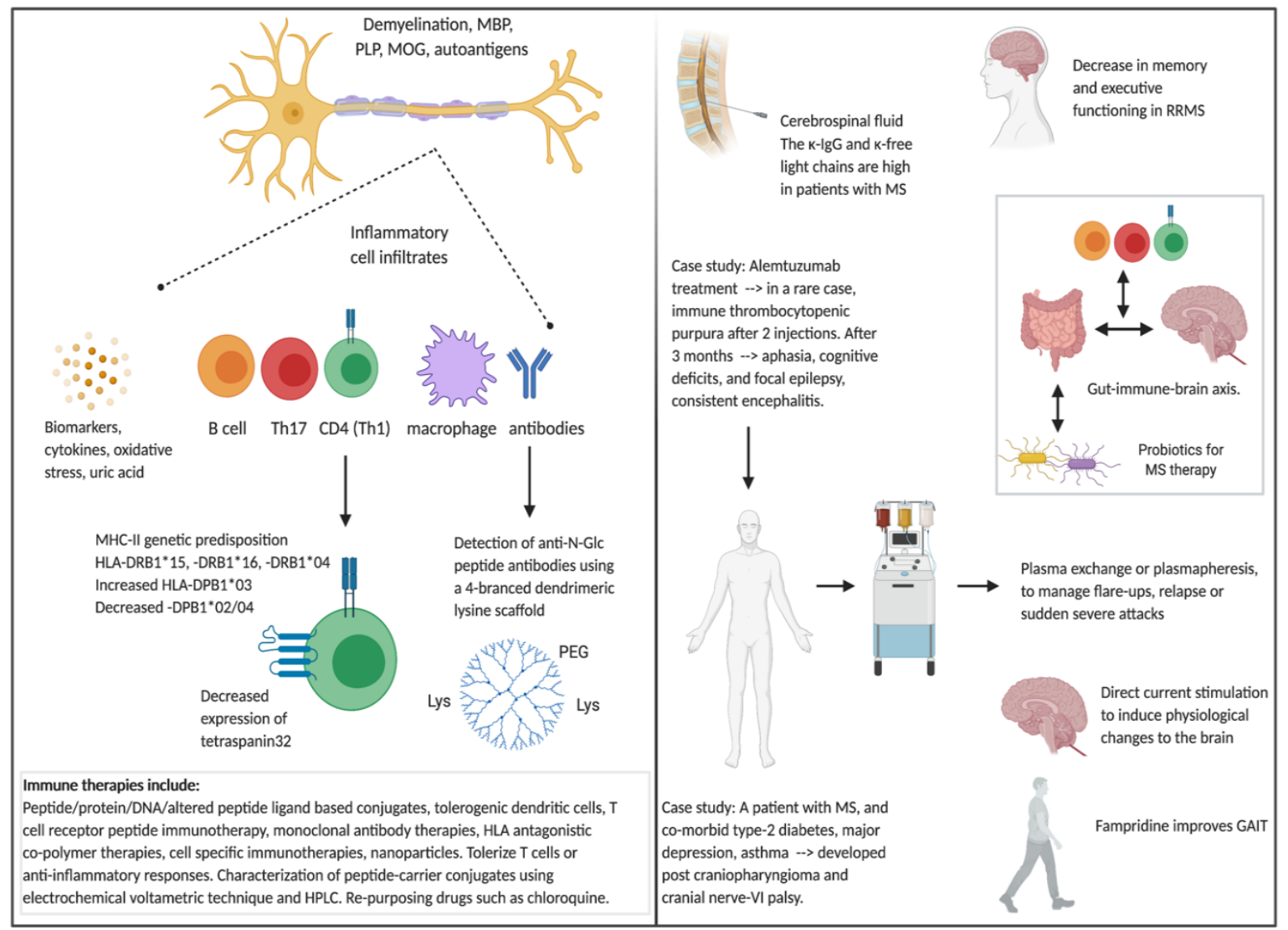

Figure 1. Summary of new advances in Multiple Sclerosis Research—Series I, papers in the Special Issue. Created with biorender.com.

A number of factors contribute to MS development, including genetic predisposition, especially those who are HLA-DR2 (HLA-DRB1*15, HLA-DRB1*16)- or HLA-DR4 (HLA-DRB1*04)-positive, environmental factors such as Epstein-Barr virus and human herpesvirus 6 exposure, and diet, such as low levels of vitamins B and D [1,5,6]. A number of health conditions are related to HLA phenotype, such as type-1 diabetes (HLA-DRB1*03 or HLA-DR3, HLA-DQB1*03 or HLA-DQ8), rheumatoid arthritis (HLA-DRB1*04), juvenile idiopathic arthritis (HLA-DRB1*08), celiac disease (HLA-DQ2, HLA-DQ8) and Graves' disease (HLA-DRB1*03, HLA-DQA1*0501). The paper by Maria Anagnostouli et al. studied the prevalence of HLA-DPB1 allele in MS patients from a Greek cohort and its association with HLA-DRB1 risk allele [7]. No significant differences were noted between early onset MS compared to adult onset MS for 23 distinct HLA-DPB1 and 12 HLA-DRB1 alleles. However, the frequency of HLA-DPB1*03 allele was significantly increased, and the frequency of HLA-DPB1*02 allele was significantly decreased, in AOMS patients compared to controls. Interestingly, the frequency of HLA-DPB1*04 allele was significantly decreased in both patients, with early onset and adult onset MS compared to controls, suggesting a protective role of this allele amongst Greek cohort patients (Figure 1) [7]. Koukoulitsa and colleagues present a nice review articulating the journey of the conformational complex between HLA-peptide with the T cell receptor of agonist peptides and their altered peptide ligands from MBP, MOG and PLP [8]. 


\section{Detection and Monitoring of Patients with MS}

Magnetic resonance imaging (MRI) has been the gold standard of diagnosing and monitoring disease by detecting brain lesions and the type of brain lesion which aids treatment decisions. In addition, other detection methods are used in combination with MRI, such as the Kurtzke Expanded Disability Status Scale (EDSS) which measures the body's function and how well it can move, as well as analysis of cerebrospinal fluid for free light chains and IgG. Together, these increase the accuracy of diagnosis of MS and are used to monitor disease progression. However, there are few simple assays available to follow up disease activity. As such, the detection of auto-antibodies from sera is a method to detect relevant biomarkers. The team by Nuti and Papini et al., developed a method to detect anti-N-glycosylated (N-Glc) peptide antibodies, using a four-branched dendrimeric lysine scaffold, linked to a polyethylene glycol-based spacer containing 19-amino acids. This efficient multivalent probe has specificity and high affinity for anti-N-Glc antibodies in patients with MS [9]. In addition, Gudowska-Sawczuk evaluated cerebrospinal fluid and sera from patients with either MS $(n=34)$ or other neurological disorders $(n=42)$ [10]. The concentrations of cerebrospinal fluid $\kappa$ free light chains $(\kappa F L C)$ and $\lambda F L C$, and sera $\kappa F L C$, as well as $\kappa F L C, \lambda F L C$, and $\kappa \operatorname{IgG}$ index, were significantly higher in patients with MS compared to those with other neurological disorders. The $\kappa I g G$ index showed the highest diagnostic power in the detection of MS with both $\mathrm{kFLC}$ index and $\mathrm{KIgG}$ indexes showing the highest diagnostic sensitivity. This study provides novel information about the diagnostic significance of four markers combined in the $\mathrm{kIgG}$ index [10] and shows that $\mathrm{kFLC}$ and $\mathrm{kIgG}$ combined in a novel algorithm may improve the detection and disease activity of MS (Figure 1).

Cognitive function refers to a range of high-level brain functions, such as the ability to learn and remember information, solve problems, focus, concentration, attention, and verbal fluency. Change in cognitive function is common in patients with advanced MS. However, Pitteri et al, showed that newly diagnosed RRMS patients ( $n=50$ ) performed worse than healthy controls $(n=36)$, in particular, in the domains of memory and executive functioning [11]. These data demonstrate that reduced cognitive functioning can be present early on during the course of disease, even in patients without evidence of cognitive impairment. As such, the cognitive impairment criteria for patients with MS should be re-evaluated and be monitored closely throughout the course of disease (Figure 1).

\section{Treatments for MS}

Treatments for MS include, interferon (IFN) beta-1a, IFN beta-1b (cytokines), fingolimod, ozanimod, siponimod (sphingosine-1-phosphate-receptor modulators), natalizumab (a monoclonal antibody against alpha4-integrin), dimethyl fumarate, glatiramer acetate, teriflunomide, cladribine, ocrelizumab (a humanized anti-CD20 monoclonal antibody) and, alemtuzumab (a humanized anti-CD52 monoclonal antibody) [1,2]. These drugs are focused on speeding recovery from relapse, slowing the progression of disease and managing MS symptoms, and in most cases, there are side effects and patients need to stop treatment due to non-tolerance of the treatment. In rare cases, more severe adverse events occur. In fact, Buscarinu et al., presented a case report of a 45 year old Italian woman with RRMS on alemtuzumab treatment who showed immune thrombocytopenic purpura after the second injection of alemtuzumab. Three months following treatment, the patient presented with transient aphasia, cognitive deficits, and focal epilepsy, consistent encephalitis [12]. Autoimmune complications following alemtuzumab treatment are generally rare, with only one previous case being reported. Furthermore, Sachinvala et al. reported a male patient with MS, and co-morbid type-2 diabetes, major depression, asthma, developed post craniopharyngioma and cranial nerve-VI palsy. Magnetic resonance imaging, Humphrey's visual filed and retinal nerve fiber thickening were used to determine changes to help the patient maintain productivity and mental state and mood (Figure 1) [13].

There is a need for the development of new treatment options which would stop progression and have little to no side effects. Immune therapies have come a long way in recent years, with a number of methods being tested in pre-clinical and clinical settings, such as peptide/protein/DNA based vaccines, tolerogenic dendritic cells, $\mathrm{T}$ cell receptor peptide immunotherapy, monoclonal antibody 
therapies (anti-integrin a-4, anti-leucine rich repeat and immunoglobin-like domain-containing protein 1 (LINGO-1), anti-CD52), HLA antagonistic co-polymer therapies, cell specific immunotherapies, peptide-carrier conjugates, all of which are extensively reviewed by Kammona and Kiparissides [14] and Metaxakis et al. [15] (Figure 1). An editorial entitled, the long road of immunotherapeutics against MS [16], highlighted 20 years of MS research of an international multi-disciplinary consortia including peptide chemistry, medicinal chemistry, protein synthesis, protein-peptide interactions, nuclear magnetic imaging, molecular modeling, molecular dynamics, molecular biology, immunology, cell biochemistry, animal research and clinical research. This multi-disciplinary consortia led to at least 10 immunotherapeutic peptide-carrier candidates to be tested in human clinical trials. In preclinical studies, these peptide-based immune modulating conjugates showed a safety profile whilst switching immune responses from pro-inflammatory to anti-inflammatory and protection against experimental autoimmune encephalomyelitis (EAE) in mouse models [3,17-24]. Characterization of peptide-carrier conjugates was demonstrated using electrochemical voltametric techniques and high-pressure liquid chromatography [25]. In addition, nanoparticles have been used to deliver MS antigens to the immune system to tolerize $\mathrm{T}$ cells or stimulate an anti-inflammatory responses, reviewed by Chountoulesi and Demetzos [26]. More recently, chloroquine, an anti-malarial drug, was shown to suppress EAE in mice by modulating dendritic cells, Th17 cells, astrocytes, oligodendrocytes and microglia. Microglia cells were also shown to secrete IL-10 and IL-12p70. These data provide evidence that drug repurposing of chloroquine may be useful to patients with MS (Figure 1) [27].

In the last ten years, the incidence of MS has increased considerably, with lifestyle and environmental factors being one of the main contributors. An informative review by Boziki and Grigoriadis et al., provide the current advances in the gut-microbiome-immune-brain axis in patients with MS with altered microbiome, and present the effects of MS treatments on gut microbiome (Figure 1) [28]. Thus, modification of gut microbiota by either dietary (such as, probiotics) or medicinal approaches is a promising approach for the management of MS. In fact, probiotics have been shown to have beneficial effects not only in the gut flora but also in modulating and maintaining a healthy immune system. Certain probiotics have been shown to have anti-inflammatory effects on immune cells (i.e., monocytes) and in disease settings, such as asthma and allergies [29,30]. The paper by Dargahi et al. showed that the probiotic Streptococcus thermophilus was able alter pro-inflammatory T cells responses against an agonist $\mathrm{MBP}_{83-99}$ peptide to an anti-inflammatory profile (Figure 1) [31]. This study suggests that the consumption of Streptococcus thermophilus may be beneficial in the management and treatment of autoimmune diseases such as MS, and further research in this area is warranted.

In addition to intravenous or oral steroids that are used as the first line of therapy for MS relapse, therapeutic plasma exchange, or plasmapheresis, is another method used to treat patients with neuromyelitis optica spectrum disorders, autoimmune encephalitis and MS, especially those with sudden, severe attacks or relapse/flare-ups. It is used in MS patients to manage disease by exchanging their plasma with 'fresh' plasma to remove pro-inflammatory cytokines and other proteins involved in auto-immune attack. In a study published by Moser et al., in this Special Issue, they compare the indications, efficacy and safety of therapeutic plasma exchange treatment in MS, autoimmune encephalitis and other immune-mediated CNS disorders and noted consistent efficacy and safety [32]. Measuring biomarkers of inflammation and oxidative stress is important to understand the efficacy of treatments. As such, Moccia et al. studied 60 patients with RRMS who were treated with IFN beta-1a or Coenzyme Q10 and monitored patients for IL-1b, IL-2R, IL-3, IL-4, IL-5, IL-6, IL-7, IL-8, IL-13, RANTES, tumor necrosis factor and uric acid (Figure 1) [33]. These serum biomarkers could be used to determine the efficacy of treatments as well as their mechanisms of action.

It is believed that transcranial magnetic stimulation motors with direct current stimulation (tDCS) intensities induce physiological changes to the brain, although the mechanism of action, as well as its validity and efficacy, are not clear. In a pilot study by Workman and colleagues, they noted that there were no immediate changes in cerebral blood flow following direct current stimulation. Hence, further work is required to enable sufficient magnitudes of intracranial electrical fields to induce 
physiological changes in the brain to patients with MS (Figure 1) [34]. During disease progression, patients with MS develop walking limitations, and fampridine is usually recommended to improve gait. In the study by Ahdab et al., fampridine was evaluated for cortical excitability effects and whether changes could predict therapeutic responses in 20 patients with MS and gait impairment [35]. It was noted that fampridine increased the excitatory intracortical processes, as shown by paired-pulse transcranial magnetic stimulation, suggesting that this could be used to select patients with MS who would be likely to experience a favorable response to fampridine (Figure 1) [35].

\section{Conclusions}

The development of drugs, immunotherapeutics and vaccines against diseases is a long process often taking researchers a lifetime. In this Special Issue, "Advances in Multiple Sclerosis Research-Series I", a range of papers were published, including MS markers, treatments, detection, monitoring and the role of the microbiome in MS. Together, all this information advances our knowledge of MS research, with promising new leads being developed in the next few years and entering human clinical trials.

Author Contributions: Conceptualization, writing, review, editing: J.M., V.A. Both authors have read and agreed to the published version of the manuscript.

Funding: The writing of this editorial received no external funding.

Acknowledgments: V.A. would like to thank the Institute for Health and Sport, Victoria University for supporting her current efforts into MS research. J.M. would like to thank the General Secretariat for Research and Technology (GSRT) and Patras Science Park for supporting his MS research.

Conflicts of Interest: The authors declare no conflict of interest.

\section{References}

1. Dargahi, N.; Katsara, M.; Tselios, T.; Androutsou, M.E.; de Courten, M.; Matsoukas, J.; Apostolopoulos, V. Multiple Sclerosis: Immunopathology and Treatment Update. Brain Sci. 2017, 7, 78. [CrossRef]

2. Katsara, M.; Apostolopoulos, V. Editorial: Multiple Sclerosis: Pathogenesis and Therapeutics. Med. Chem. 2018, 14, 104-105. [CrossRef] [PubMed]

3. Katsara, M.; Matsoukas, J.; Deraos, G.; Apostolopoulos, V. Towards immunotherapeutic drugs and vaccines against multiple sclerosis. Acta Biochim. Biophys. Sin. 2008, 40, 636-642. [CrossRef] [PubMed]

4. Basile, M.S.; Mazzon, E.; Mangano, K.; Pennisi, M.; Petralia, M.C.; Lombardo, S.D.; Nicoletti, F.; Fagone, P.; Cavalli, E. Impaired Expression of Tetraspanin 32 (TSPAN32) in Memory T Cells of Patients with Multiple Sclerosis. Brain Sci. 2020, 10, 52. [CrossRef] [PubMed]

5. Nemazannikova, N.; Mikkelsen, K.; Stojanovska, L.; Blatch, G.L.; Apostolopoulos, V. Is there a Link between Vitamin B and Multiple Sclerosis? Med. Chem. 2018, 14, 170-180. [CrossRef] [PubMed]

6. Virtanen, J.O.; Jacobson, S. Viruses and multiple sclerosis. CNS Neurol. Disord. Drug Targets 2012, 11, 528-544. [CrossRef] [PubMed]

7. Anagnostouli, M.; Artemiadis, A.; Gontika, M.; Skarlis, C.; Markoglou, N.; Katsavos, S.; Kilindireas, K.; Doxiadis, I.; Stefanis, L. HLA-DPB1*03 as Risk Allele and HLA-DPB1*04 as Protective Allele for Both Earlyand Adult-Onset Multiple Sclerosis in a Hellenic Cohort. Brain Sci. 2020, 10, 374. [CrossRef]

8. Koukoulitsa, C.; Chontzopoulou, E.; Kiriakidi, S.; Tzakos, A.G.; Mavromoustakos, T. A Journey to the Conformational Analysis of T-Cell Epitope Peptides Involved in Multiple Sclerosis. Brain Sci. 2020, 10, 356. [CrossRef]

9. Nuti, F.; Fernandez, F.R.; Sabatino, G.; Peroni, E.; Mulinacci, B.; Paolini, I.; Pisa, M.D.; Tiberi, C.; Lolli, F.; Petruzzo, M.; et al. A Multiple N-Glucosylated Peptide Epitope Efficiently Detecting Antibodies in Multiple Sclerosis. Brain Sci. 2020, 10, 453. [CrossRef]

10. Gudowska-Sawczuk, M.; Tarasiuk, J.; Kulakowska, A.; Kochanowicz, J.; Mroczko, B. Kappa Free Light Chains and IgG Combined in a Novel Algorithm for the Detection of Multiple Sclerosis. Brain Sci. 2020, 10, 324. [CrossRef] 
11. Pitteri, M.; Ziccardi, S.; Dapor, C.; Guandalini, M.; Calabrese, M. Lost in Classification: Lower Cognitive Functioning in Apparently Cognitive Normal Newly Diagnosed RRMS Patients. Brain Sci. 2019, 9, 321. [CrossRef] [PubMed]

12. Buscarinu, M.C.; Fornasiero, A.; Pellicciari, G.; Renie, R.; Landi, A.C.; Bozzao, A.; Cappelletti, C.; Bernasconi, P.; Ristori, G.; Salvetti, M. Autoimmune Encephalitis and CSF Anti-GluR3 Antibodies in an MS Patient after Alemtuzumab Treatment. Brain Sci. 2019, 9, 299. [CrossRef]

13. Sachinvala, N.D.; Stergiou, A.; Haines, D.E.; Kocharian, A.; Lawton, A. Post-Craniopharyngioma and Cranial Nerve-VI Palsy Update on a MS Patient with Major Depression and Concurrent Neuroimmune Conditions. Brain Sci. 2019, 9, 281. [CrossRef] [PubMed]

14. Kammona, O.; Kiparissides, C. Recent Advances in Antigen-Specific Immunotherapies for the Treatment of Multiple Sclerosis. Brain Sci. 2020, 10, 333. [CrossRef]

15. Metaxakis, A.; Petratou, D.; Tavernarakis, N. Molecular Interventions towards Multiple Sclerosis Treatment. Brain Sci. 2020, 10, 299. [CrossRef] [PubMed]

16. Apostolopoulos, V.; Rostami, A.; Matsoukas, J. The Long Road of Immunotherapeutics against Multiple Sclerosis. Brain Sci. 2020, 10, 288. [CrossRef]

17. Katsara, M.; Deraos, G.; Tselios, T.; Matsoukas, J.; Apostolopoulos, V. Design of novel cyclic altered peptide ligands of myelin basic protein MBP83-99 that modulate immune responses in SJL/J mice. J. Med. Chem. 2008, 51, 3971-3978. [CrossRef]

18. Katsara, M.; Deraos, G.; Tselios, T.; Matsoukas, M.T.; Friligou, I.; Matsoukas, J.; Apostolopoulos, V. Design and synthesis of a cyclic double mutant peptide (cyclo(87-99)[A91,A96]MBP87-99) induces altered responses in mice after conjugation to mannan: Implications in the immunotherapy of multiple sclerosis. J. Med. Chem. 2009, 52, 214-218. [CrossRef]

19. Katsara, M.; Deraos, S.; Tselios, T.V.; Pietersz, G.; Matsoukas, J.; Apostolopoulos, V. Immune responses of linear and cyclic PLP139-151 mutant peptides in SJL/J mice: Peptides in their free state versus mannan conjugation. Immunotherapy 2014, 6, 709-724. [CrossRef]

20. Katsara, M.; Yuriev, E.; Ramsland, P.A.; Deraos, G.; Tselios, T.; Matsoukas, J.; Apostolopoulos, V. A double mutation of $\mathrm{MBP}(83-99)$ peptide induces IL-4 responses and antagonizes IFN-gamma responses. J. Neuroimmunol. 2008, 200,77-89. [CrossRef]

21. Katsara, M.; Yuriev, E.; Ramsland, P.A.; Deraos, G.; Tselios, T.; Matsoukas, J.; Apostolopoulos, V. Mannosylation of mutated MBP83-99 peptides diverts immune responses from Th1 to Th2. Mol. Immunol. 2008, 45, 3661-3670. [CrossRef] [PubMed]

22. Katsara, M.; Yuriev, E.; Ramsland, P.A.; Tselios, T.; Deraos, G.; Lourbopoulos, A.; Grigoriadis, N.; Matsoukas, J.; Apostolopoulos, V. Altered peptide ligands of myelin basic protein ( MBP87-99) conjugated to reduced mannan modulate immune responses in mice. Immunology 2009, 128, 521-533. [CrossRef] [PubMed]

23. Lourbopoulos, A.; Deraos, G.; Matsoukas, M.T.; Touloumi, O.; Giannakopoulou, A.; Kalbacher, H.; Grigoriadis, N.; Apostolopoulos, V.; Matsoukas, J. Cyclic MOG35-55 ameliorates clinical and neuropathological features of experimental autoimmune encephalomyelitis. Bioorg. Med. Chem. 2017, 25, 4163-4174. [CrossRef] [PubMed]

24. Lourbopoulos, A.; Matsoukas, M.T.; Katsara, M.; Deraos, G.; Giannakopoulou, A.; Lagoudaki, R.; Grigoriadis, N.; Matsoukas, J.; Apostolopoulos, V. Cyclization of PLP139-151 peptide reduces its encephalitogenic potential in experimental autoimmune encephalomyelitis. Bioorg. Med. Chem. 2018, 26, 2221-2228. [CrossRef]

25. Deskoulidis, E.; Petrouli, S.; Apostolopoulos, V.; Matsoukas, J.; Topoglidis, E. The Use of Electrochemical Voltammetric Techniques and High-Pressure Liquid Chromatography to Evaluate Conjugation Efficiency of Multiple Sclerosis Peptide-Carrier Conjugates. Brain Sci. 2020, 10, 577. [CrossRef]

26. Chountoulesi, M.; Demetzos, C. Promising Nanotechnology Approaches in Treatment of Autoimmune Diseases of Central Nervous System. Brain Sci. 2020, 10, 338. [CrossRef]

27. Thome, R.; Boehm, A.; Ishikawa, L.L.W.; Casella, G.; Munhoz, J.; Ciric, B.; Zhang, G.X.; Rostami, A. Comprehensive Analysis of the Immune and Stromal Compartments of the CNS in EAE Mice Reveal Pathways by Which Chloroquine Suppresses Neuroinflammation. Brain Sci. 2020, 10, 348. [CrossRef]

28. Boziki, M.K.; Kesidou, E.; Theotokis, P.; Mentis, A.A.; Karafoulidou, E.; Melnikov, M.; Sviridova, A.; Rogovski, V.; Boyko, A.; Grigoriadis, N. Microbiome in Multiple Sclerosis; Where Are We, What We Know and Do Not Know. Brain Sci. 2020, 10, 234. [CrossRef] 
29. Dargahi, N.; Johnson, J.; Apostolopoulos, V. Streptococcus thermophilus alters the expression of genes associated with innate and adaptive immunity in human peripheral blood mononuclear cells. PLoS ONE 2020, 15, e0228531. [CrossRef]

30. Dargahi, N.; Johnson, J.; Donkor, O.; Vasiljevic, T.; Apostolopoulos, V. Immunomodulatory effects of probiotics: Can they be used to treat allergies and autoimmune diseases? Maturitas 2019, 119, $25-38$. [CrossRef]

31. Dargahi, N.; Matsoukas, J.; Apostolopoulos, V. Streptococcus thermophilus ST285 Alters Pro-Inflammatory to Anti-Inflammatory Cytokine Secretion against Multiple Sclerosis Peptide in Mice. Brain Sci. 2020, 10, 126. [CrossRef] [PubMed]

32. Moser, T.; Harutyunyan, G.; Karamyan, A.; Otto, F.; Bacher, C.; Chroust, V.; Leitinger, M.; Novak, H.F.; Trinka, E.; Sellner, J. Therapeutic Plasma Exchange in Multiple Sclerosis and Autoimmune Encephalitis: A Comparative Study of Indication, Efficacy and Safety. Brain Sci. 2019, 9, 267. [CrossRef] [PubMed]

33. Moccia, M.; Capacchione, A.; Lanzillo, R.; Carbone, F.; Micillo, T.; Matarese, G.; Palladino, R.; Brescia Morra, V. Sample Size for Oxidative Stress and Inflammation When Treating Multiple Sclerosis with Interferon-beta1a and Coenzyme Q10. Brain Sci. 2019, 9, 259. [CrossRef]

34. Workman, C.D.; Ponto, L.L.B.; Kamholz, J.; Rudroff, T. No Immediate Effects of Transcranial Direct Current Stimulation at Various Intensities on Cerebral Blood Flow in People with Multiple Sclerosis. Brain Sci. 2020, 10, 82. [CrossRef]

35. Ahdab, R.; Shatila, M.M.; Shatila, A.R.; Khazen, G.; Freiha, J.; Salem, M.; Makhoul, K.; El Nawar, R.; El Nemr, S.; Ayache, S.S.; et al. Cortical Excitability Measures May Predict Clinical Response to Fampridine in Patients with Multiple Sclerosis and Gait Impairment. Brain Sci. 2019, 9, 357. [CrossRef] [PubMed]

Publisher's Note: MDPI stays neutral with regard to jurisdictional claims in published maps and institutional affiliations. 